\title{
Length of Stay and Tourism Facility Assessment: The Viewpoint of Malaysian Tourists at Langkawi
}

\author{
Mastura Jaafar ${ }^{1}$, Mana Khoshkam² \\ ${ }^{1,2}$ School of Housing, Building and Planning, Universiti Sains Malaysia, 11800 Penang, Malaysia
}

\begin{abstract}
This investigation employed partial least square analysis to scrutinize factors influencing the social perceptions of Malaysian tourists of tourism facilities at an island tourism destination. It focuses on the effect of one particular socio-demographic variable, length of stay, on consumer satisfaction. Data was collected from a major tourism destination at Langkawi, Malaysia. The results indicate that length of stay has an effect on tourists' social perceptions and contributes to their dissatisfaction with the destination. Tourists who stayed more than 10 days were less satisfaction than those who stayed for less than 10 days. The implications of this finding and recommendations for further study are discussed as well.
\end{abstract}

\section{Introduction}

Langkawi is considered as a major tourism destination in Malaysia which plays an important role in the country's tourism industry. Ever since the Sixth Malaysia Plan (1991 - 1995), efforts had been undertaken to improve and promote Langkawi's tourism facilities [1]. But while increasing the volume of tourists and ensuring their satisfaction is a priority, various problems exist in relation to the quality of attractions, including issues with safety, poor maintenance, vandalism of facilities, and other issues [2].

One of Langkawi's more popular tourist attractions is the Oriental Village. Owing to this popularity, the Oriental Village was chosen as the focus of this study, the aim of which is to examine how length of stay (LoS), social perceptions (SP), and social facilities (SF) affect customer satisfaction (CS). The research model and hypothesized relationships were tested using the Partial Least Squares (PLS) approach.

\section{Literature}

\subsection{Length of stay}

There are few studies that have used duration models in the context of tourism [3]. LoS is concerned with the duration of a tourist's stay at a destination [4]. However, tourists are often unsure about how long they should spend at a destination and this is often a decision best made when planning ones travel [5]. In part, the determination about LoS is guided by external demands (esp. necessity to return to work), but is also be informed by economic considerations. Economic factors also influence the 
range of activities that tourists undertake while visiting a destination and their choice of accommodation. Tourist socio-demographic information and their expectations regarding the quality of the facilities and services is best recorded when the tourist is departing. This information tells us about tourist profiles, their destination experiences, and their expectations [5, 6]. Davis and Mangan (1992) [7] suppose that LoS determines what activities a tourist engages in and their economic impact on the host community. Therefore, LoS can be considered predictive of tourist spending [7-9].

Additionally, Butter (1975) [10] identified five tourist-related factors that influence tourist interactions with local residents; including the number of visitors, LoS, ethnic characteristics, economic and socio-cultural characteristics, and activities undertaken during their stay. Chen and Hsu (2000) [11] reported that LoS, among other variables, affects how Korean tourists' measure the attractiveness of a destination. But despite the growth of the tourism literature, few studies have investigated LoS and tourism facilities in Malaysia. This study seeks to examine the relationship between several variables to better understand CS in relation to the facilities at Langkawi's Oriental Village. Therefore, the primary research hypothesis for this study was as follows:

\section{H1: LoS has a positive effect on SP}

Whilst LoS pertains to the amount of time that a tourist spends at a destination, it does not include the time spent travelling [12]. Furthermore, LoS does not include time spent at other destinations. For example, LoS at Langkawi is calculated separately from LoS at Penang; although both could be combined to determine LoS in Malaysia. Ascertaining LoS allows for key stakeholders to develop appropriate tourist infrastructure [12]. Based on the literature review above, we hypothesized that:

\section{H2: LoS has a positive effect on SF}

Previous studies have demonstrated a positive relationship between LoS and CS with a destination [13]. Beachside destinations tend to be favoured by tourists and receive a high number of repeat visitors [14]. Therefore, satisfaction with a previous visit positively influences the decision to return [15], and this sense of satisfaction is itself influenced by aspects of the destination [16]. Therefore, we hypothesized that:

\section{H3: LoS has a positive effect on CS}

\subsection{Tourism facilities}

In the context of tourism, satisfaction refers to the perceived sum of the relationship between ones expectations of a tourism product and one's actual experience of consuming said product. If a product does not meet expectations, dissatisfaction results [17]. Previous studies suggest that perceptions of service quality are correlated with value satisfaction, and that satisfaction affects loyalty and postconsumption behaviors [18]. Accordingly, we hypothesized that:

H4: SP will influence CS

\subsection{Customer satisfaction}

With reference to some researchers, CS has its origin within the individual, in how they compare their expectations of a product or service with the actual product or service that was delivered. Furthermore, it has been hypothesized that CS can be measured behaviorally. To illustrate, definitive satisfaction or dissatisfaction with a product might be expressed through the voluntarily writing a letter to complain or compliment a product. Similarly, a tourist might be complimentary of their experience of a product, but be dissatisfied with the facilities. Satisfaction might be expressed though repeat visits to a destination or through "word-of-mouth" recommendations [2]. 
Sharpley [4] notes that satisfaction plays an important role in the planning of marketable tourism products and services. However, despite the apparent importance of tourist satisfaction, few papers have defined the concept. In one paper, tourist satisfaction was described as the total sum of the quality of a visitor's experience; the psychological state or outcome produced as a result of the visitor's interaction with the various aspects of a tourist product or service [19]. With this definition of tourist satisfaction in mind, there is a paucity of research concerning the relationship between tourist satisfaction and tourist facilities. In one of the few studies of its kind, Sekaran and Bougie (2010) [20] report that SF, such as friendly/quality services, and physical facilities (i.e. lodgings) are significant contributors toward a tourist's overall satisfaction. Therefore, we hypothesized that:

H5: SF will influence CS

\section{Research context and research model}

In this particular study, we investigated the contribution made by the tourism facilities at Langkawi's Oriental Village to CS, using how much a customer was willing to pay for these products as a behavioral measure of CS. To this end, we proposed five research hypotheses to be tested:

H1: LoS has a positive effect on SP

H2: LoS has a positive effect on SF

H3: LoS has a positive effect on CS

H4: SP will influence CS

H5: SF will influence CS

The hypothetical relationships between these variables, IV (Demographic characteristics), DV (Tourism Facilities), and DV (Willingness to pay), are illustrated in Fig. 1, noting that satisfaction is the product of the interaction between SP and LoS, and between SF and LoS. LoS itself, however, leads more directly to the experience of satisfaction.

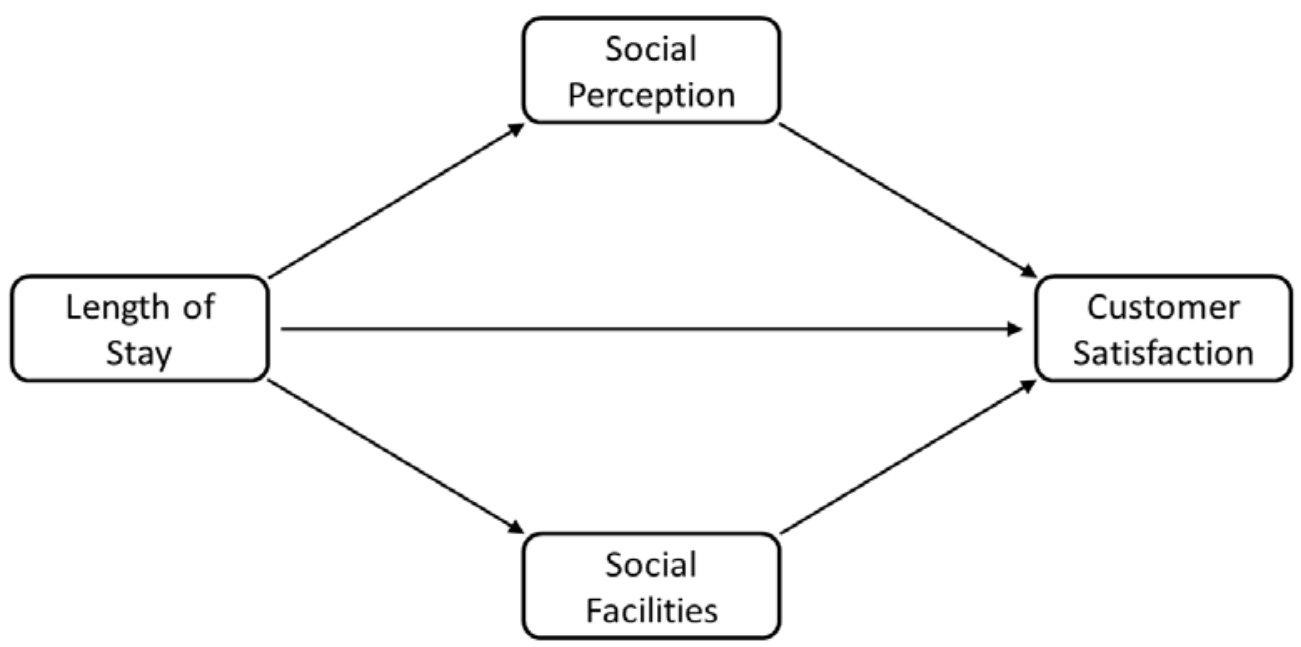

Figure 1. Research Model

\section{Research Method}

We targeted domestic Malaysian tourists visiting Langkawi in this study. While Langkawi receives a number of international tourists, cluster sampling allowed us to focus our attention on domestic 
tourists. For the first step, we divided Langkawi into five regions based on the points of the compass. Secondly, a list of tourist attractions was developed for each region, including the identification of a "hot spot" attraction that saw the most visitors. For the Northern region of Langkawi, the "hot spot" attraction was the Oriental Village. In the final step, one on of these five "hot spots" was chosen at random.

\subsection{Data Collection}

The self-report questionnaire used in this study was divided into four sections; the first section collected demographic information, including LoS. The second section sought to investigate the respondent's SPs. The third section inquired about their views on the Oriental Village's SF. In the final section, respondents were asked about their satisfaction and willingness to pay for various attractions. Data collection was conducted over two weeks during March 2014. Of the 800 questionnaires distributed, only 366 questionnaires were returned as complete.

\subsection{Measures and Assessment of Goodness of Measures}

The questionnaire contained 49 question items, 35 of which used a six-point Likert-type scale, to gather data on each construct. The items were adapted from the existing literature and modified for the purposes of measuring the facilities at the target location.

\subsection{Goodness of Measures}

Table 1 describes the factor loadings for the research model. Using multivariate analysis, we assigned a cut-off point to the factor loadings to regard a loading of 0.5 as significant [21]. Moreover, the questionnaire items tended to load highly on the target variables and lowly on other constructs, thereby confirming the construct validity. Convergent validity was determined based on a combination of composite reliability (CR), factor loadings, and the average variance extracted (AVE) [21]. All values loaded above 0.6.

CR indicates the degree to which a construct's indicators relate to the latent variables and should ideally exceed 0.7 [21]. We determined that the CR of our construct indicators ranged from 0.857 to 0.919 (Table 2), which was statistically acceptable.

Table 1. Factor Loading.

\begin{tabular}{|l|c|c|c|}
\hline Indicator & SP & CS & SF \\
\hline Social_B2 & 0.732 & & \\
\hline Social_B4 & 0.787 & & \\
\hline Social_B6 & 0.736 & & \\
\hline Social_B7 & 0.841 & & \\
\hline Social_C4 & & & 0.922 \\
\hline Social_C5 & & & 0.912 \\
\hline Social_C7 & & & 0.855 \\
\hline
\end{tabular}




\begin{tabular}{|l|l|c|l|}
\hline Willing.to.pay_D1_1 & & 0.766 & \\
\hline Willing.to.pay_D3_1 & & 0.795 & \\
\hline Willing.to.pay_D4_1 & & 0.820 & \\
\hline Willing.to.pay_D5_1 & & 0.835 & \\
\hline Willing.to.pay_D6_1 & & 0.800 & \\
\hline Willing.to.pay_D7_1 & & 0.837 & \\
\hline
\end{tabular}

Table 2. Results of measurement model

\begin{tabular}{|l|c|c|c|c|}
\hline & AVE & $\begin{array}{c}\text { Composite } \\
\text { Reliability }\end{array}$ & $\mathbf{R}^{2}$ & $\begin{array}{c}\text { Cronbach's } \\
\text { Alpha }\end{array}$ \\
\hline SP & 0.601 & 0.857 & 0.009 & 0.783 \\
\hline LoS & - & - & - & - \\
\hline CS & 0.654 & 0.919 & 0.106 & 0.895 \\
\hline SF & 0.804 & 0.925 & 0.007 & 0.878 \\
\hline
\end{tabular}

AVE measures the amount of variance a construct indicator relative to measurement errors. The AVE should be more than 0.5 to justify the inclusion of a construct [21]. In the present study, the AVE was in the range of 0.601 and 0.804 (Table 2). We used the Cronbach's alpha coefficient to test the reliability of the indicators. The Cronbach's alpha coefficient, AVE, and $\mathrm{R}^{2}$ indicating the reliability of the measurements and their internal consistency is summarized in Table 2.

Discriminant validity ensures that the construct indicators are sufficiently different from one another. We describe the discriminant validity of our indicators in Table 3, where the diagonal elements are larger than the off-diagonal elements on the same row and column, alluding to discrimination. In short, our measurement model showed both convergent and discriminant validity.

Table 3. Disciminant validity

\begin{tabular}{|l|c|c|c|c|}
\hline & SP & LoS & CS & SF \\
\hline SP & $\mathbf{0 . 7 7 5}$ & & & \\
\hline LoS & 0.094 & $\mathbf{1 . 0 0 0}$ & & \\
\hline CS & 0.232 & -0.130 & $\mathbf{0 . 8 0 9}$ & \\
\hline SF & 0.346 & -0.086 & 0.254 & $\mathbf{0 . 8 9 7}$ \\
\hline
\end{tabular}


Table 4 summarizes the results of testing the validity of the model's constructs. The result shows that all three constructs (i.e. SP, social facility, and willingness to pay) were valid indicators according to the parameter estimates and their statistical significance [22].

Table 4. Results of the Construct Model.

\begin{tabular}{|c|c|c|c|c|}
\hline & $\begin{array}{c}\text { Original Sample } \\
(\mathrm{O})\end{array}$ & $\begin{array}{l}\text { Standard } \\
\text { Error }\end{array}$ & $\begin{array}{c}T- \\
\text { statistics }\end{array}$ & $P$ Values \\
\hline & 0.238 & 0.072 & 3.322 & 0.001 \\
\hline & 0.325 & 0.061 & 5.324 & 0.000 \\
\hline & 0.293 & 0.073 & 4.011 & 0.000 \\
\hline & 0.421 & 0.058 & 7.197 & 0.000 \\
\hline Social_C4־SF & 0.405 & 0.047 & 8.569 & 0.000 \\
\hline Social_C5 SF & 0.368 & 0.038 & 9.604 & 0.000 \\
\hline Social_C7־SF & & 0.052 & 6.507 & 0.000 \\
\hline Willing.to.pay_D1_1ヶCS & Social_B2 $\leftarrow$ SP & 0.034 & 5.122 & 0.000 \\
\hline 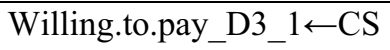 & Social_B4־SP & 0.033 & 8.157 & 0.000 \\
\hline 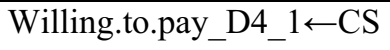 & Social_B6 $\leftarrow$ SP & 0.032 & 8.033 & 0.000 \\
\hline 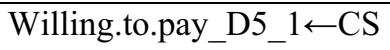 & Social_B7 & 0.023 & 7.519 & 0.000 \\
\hline Willing.to.pay_D6_1ヶCS & 0.173 & 0.035 & 4.973 & 0.000 \\
\hline 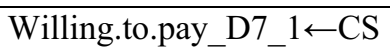 & 0.185 & 0.023 & 8.034 & 0.000 \\
\hline
\end{tabular}

\subsection{Hypothesis Testing}

A path analysis of the hypotheses was generated to test the relationships between the variables (Table 5 and Fig. 2). The $\mathrm{R}^{2}$ for the relationships between the three variables and satisfaction was 0.106 , suggesting that $10.6 \%$ of the variance of satisfaction was explained by respondent's SP, their perception of SF, and their LoS. SP and SF $(b=0.185, b=0.181, p<0.0 .1)$ were positively related to CS, whereas LoS was not significant. Also, the relationship between LoS and SF was not significant. Therefore, hypotheses H1, H3, and H5 were supported, while H2 and H4 were not supported. 
4ICTR

Table 5. Path Coefficient, $\beta$ and Hypothesis Testing

\begin{tabular}{|c|c|c|c|c|c|c|}
\hline & $\boldsymbol{B}$ & $\left(\boldsymbol{F}^{2}\right)$ & Standard Error & T-statistic & P-values & Supported \\
\hline $\mathrm{SP} \rightarrow \mathrm{CS}$ & 0.185 & 0.033 & 0.062 & 2.995 & 0.003 & YES \\
\hline $\mathrm{LoS} \rightarrow \mathrm{SP}$ & 0.094 & 0.007 & 0.061 & 1.390 & 0.165 & NO \\
\hline $\mathrm{LoS} \rightarrow \mathrm{CS}$ & -0.129 & 0.017 & 0.056 & 2.254 & 0.025 & YES \\
\hline $\mathrm{LoS} \rightarrow \mathrm{SF}$ & -0.086 & 0.008 & 0.078 & 1.131 & 0.259 & NO \\
\hline $\mathrm{SF} \rightarrow \mathrm{CS}$ & 0.181 & 0.031 & 0.052 & 3.455 & 0.001 & YES \\
\hline
\end{tabular}

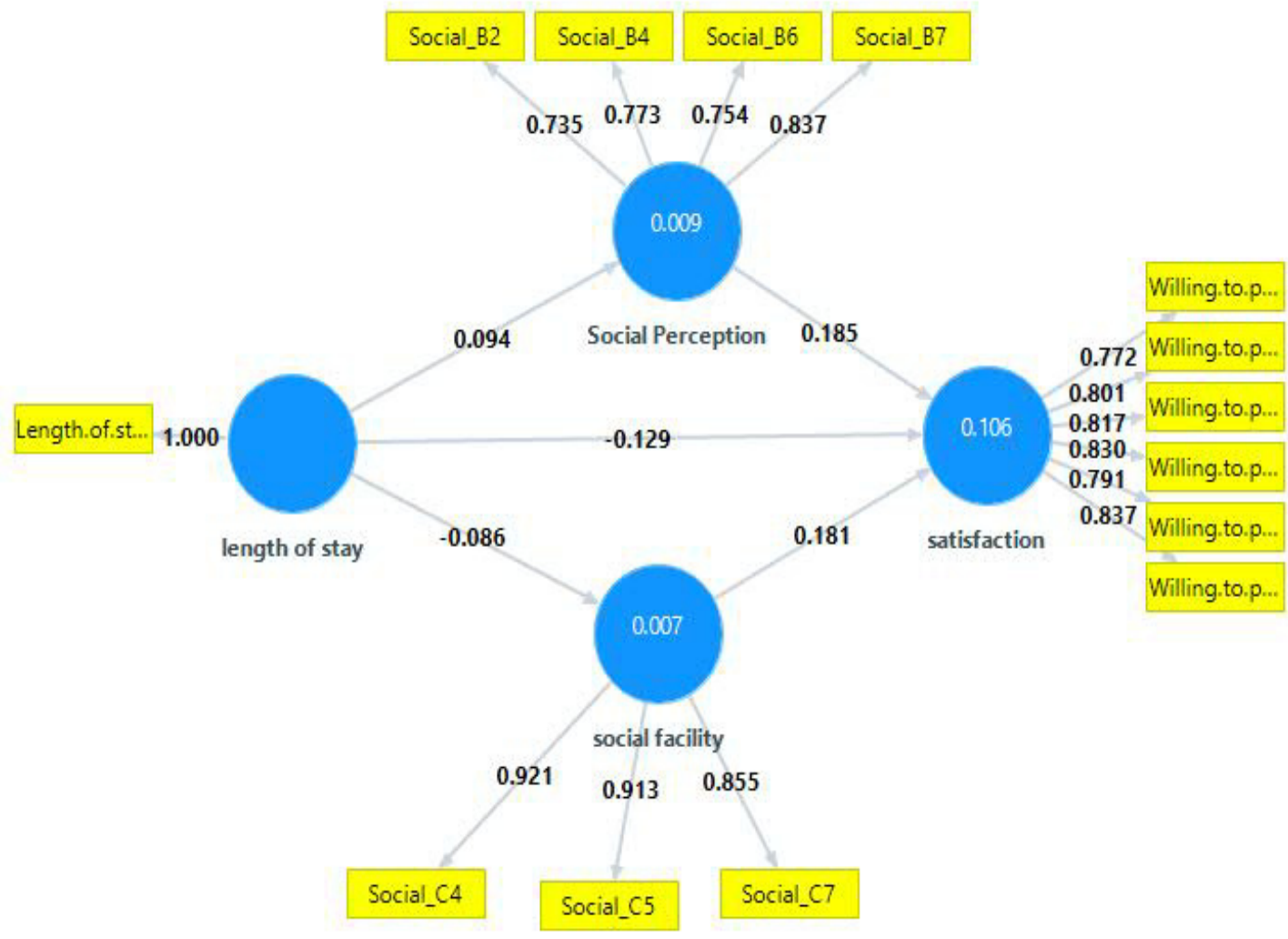

Figure 2. Final Model

These result indicate a positive and direct relationship between SP and CS ( $\beta=0.185$, Std $=0.062$, $f^{2}=0.33, t$-statistic $=2.99, P$-value $\left.<0.05\right)$. Furthermore, LoS and SP were negatively related, a finding not supported by any previous studies. Also, LoS and CS were positively related $(B=-0.129$, $\mathrm{Std}=0.056, f^{2}=0.017, t$-statistic $=2.254, P$-value $\left.<0.05\right)$. This indicates that LoS has an effect on SP and contributed toward the dissatisfaction of visitors; those respondents who stayed for more than 10 
days being less satisfied than those who stayed for less. Also, there was negative relationship between LoS and SF $(\beta=-0.086, t$-statistic $=1.131, P$-value $<0.05)$. Furthermore, the relationship between SF and CS was significant $\left(\beta=-0.181\right.$, Std. $=0.052, f^{2}=0.031, t$-statistic $=3.455, P$-value $\left.<0.05\right)$.

\section{Discussion and Conclusion}

In particular, the results of this study allude the imperative for improvements in the SF of Langkawi's Oriental Village. Previous studies have indicated that understanding tourist LoS might help policymakers and planners to develop appropriate tourism infrastructure and packages [16]. This study expands on our existing knowledge in regard to tourism facilities and satisfaction by examining the issue in the context of Malaysian domestic tourism. Therefore, Langkawi's Oriental Village was the subject for this investigation.

We found that the LoS had a significant effect on SP, which was supported the by a previous study [16]. However, we also found dissatisfaction among the visitors to the Oriental Village; those who stayed for more than 10 days were less satisfied than those who had stayed for less. This finding was in contrast to previous studies finding a positive relationship between LoS and CS [13-16]. We also identified a negative relationship between LoS and SF, again in contrast to previous studies [23].

Consequently, we argue the importance of improving the tourism facilities, particularly the SF, at the Oriental Village in Langkawi. It is noteworthy to examine CS and CP in regarding to trip duration in the area and experiences with different tourist facilities. Again, this highlights the imperative to continue developing the tourism industry in this area.

We demonstrated a positive and significant link between LoS in relation to SP, SF, and CS (esp. willingness to pay). It is crucial to understand the various perceptions and perspectives of tourists visiting an area for the first or second time. For further study, the relationship between these variables during subsequent visits might be examined.

\section{References}

1. J.A. Ibrahim, M.Z. Ahmad, Pelancongan Langkawi 1987 - 2010: Pencapaian dan cabaranmasadepan. In: Persidangan Kebangsaan Ekonomi Malaysia, Hotel Everly Resort, Melaka. (Didapati, Malaysia, 2011)

2. S. Abdullah, A.A. Razak, A. Marzuki, M. Jaafar, Assessing tourist satisfaction with the facilities provided at Langkawi island gateway jetty terminals, Liburna, 2, 2 (2013)

3. C.P.Barros, L.P.Machado, The length of stay in tourism Ann. Tour. Res, 37, 3, 692-706 (2010)

4. R. Sharpley, Tourism, tourists and society (ELM Publications, Huntingdon, 1999)

5. A. Decrop, D.Snelders, Planning the summer vacation: an adaptable and opportunistic process, Ann. Tour. Res 31, 4, 1008-1030 (2004)

6. B. Bargeman, V. Poel, The role of routines in the decision making process of Dutch vacationers, Tour. Manage 27, 4, 707-720(2006)

7. B. Davies, J.Mangan, Family expenditure on hotels and holidays', Ann. Tour. Res 19, 4, 691699 (1992)

8. P. Legoherel, Toward a market segmentation of the tourism trade: expenditure levels and consumer behavior instability, J._Travel Tour. Mark 37, 1, 19-39 (1998)

9. C. Mok, T. Iverson, Expenditure-based segmentation: Taiwanese tourists to Guam, Tour. Manage 21, 3, 299-305 (2000)

10. R.W. Butler, Tourism as an agent of social change, Proceedings of the international geographical union's working group on the geography of tourism and recreation, 85-90 (Trent University, Ontario, 1975)

11. J.S. Chen, C.H.C. Hsu, J. Measurement of Korean tourists' perceived images of overseas destinations, Travel Res 38, 4, 411-416 (2000)

12. G.E. Santos, R. Vicent, J. Rey-Maquieira, Length of Stay at Multiple Destinations of Tourism Trips in Brazil, J. Travel Tour. Res 21, 1-13 (2014) 
13. L. Festinger, A theory of social comparison processes, Human Relations 7, 117-140 (1954)

14. A. Beerli, J.D. Martin, Factors influencing destination image, Ann. Tour. Res 31, 4, 657-681 (2004)

15. M. Kozak, Repeaters' behavior at two distinct destinations, Ann. Tour. Res 28, 3, 785-808 (2001)

16. M. Kozak, 'Measuring tourist satisfaction with multiple destination attributes, Tour. Anal 7, 229240 (2003)

17. R.L. Oliver, Whence consumer loyalty? J. Mark 63, 33-44 (1999)

18. C.F. Chen, D. Tsai, How destination image and evaluative factors affect behavioral intentions? Tour. Manage 28, 1115 -1122 (2007)

19. M. Meng, Y. Tepanon, M. Uysal, Measuring tourist satisfaction by attribute and motivation: The case of a nature-based resort, J. Vac. Mark 14, 1, 41-56 (2008)

20. U. Sekaran, R. Bougie, Research Methods for Business: A Skill Building Approach (Wiley, London, 2010)

21. J.F. Hair, W.C. Black, B.J. Babin, R.E. Anderson, Multivariate data analysis (Prentice-Hall, Upper Saddle River, 2010)

22. W.S. Chow, L.S. Chan, Social network and shared goals in organizational knowledge sharing, Inf Manag 45, 7, 24-30 (2008)

23. C. Thrane, E. Farstad, Tourists' Length of Stay: The case of international summer visitors to Norway, Tour. Econ 18, 5, 1069-1082 (2012) 